This article is licensed under the Creative Commons Attribution-NonCommercial 4.0 International License (CC BY-NC) (http://www.karger.com/Services/OpenAccessLicense). Usage and distribution for commercial purposes requires written permission.

\title{
Hepatic Encephalopathy Mimicking Acute Dominant Middle Cerebral Artery Ischemic Stroke: A Case Report
}

\author{
Kyan Younes $^{\mathrm{a}} \quad$ Nicole R. Gonzales ${ }^{\mathrm{b}} \quad$ Amrou Sarraj $^{\mathrm{b}} \quad$ Eliana Bonfante ${ }^{\mathrm{c}}$ \\ Amanda Jagolino-Cole ${ }^{b}$ \\ aMemory and Aging Center, University of California at San Francisco, San Francisco, CA, \\ USA; ${ }^{b}$ Institute for Stroke and Cerebrovascular Disease, University of Texas Health Science \\ Center at Houston McGovern Medical School, Houston, TX, USA; 'Department of \\ Diagnostic and Interventional Imaging, University of Texas Health Science Center at \\ Houston McGovern Medical School, Houston, TX, USA
}

\section{Keywords}

Stroke · Hepatic encephalopathy · Hyperammonemia - Transaminitis - Stroke mimic - Digital subtraction angiography

\begin{abstract}
Hepatic encephalopathy and hyperammonemia are common in the setting of liver disease and have been associated with both generalized and focal neurological deficits. We report a case of hepatic encephalopathy with transaminitis in the setting of hyperammonemia clinically mimicking acute dominant middle cerebral artery (MCA) syndrome. A 59-year-old righthanded woman had new-onset expressive aphasia, left gaze deviation, and right hemiparesis consistent with MCA stroke. Her symptoms began $12 \mathrm{~h}$ after transarterial chemoembolization, a procedure to embolize blood supply and provide cytotoxic agents to a hepatocellular carcinoma tumor. Thrombocytopenia and age-indeterminate hypodensities on brain CT precluded intravenous thrombolytic administration. MRI revealed predominantly dominant hemisphere
\end{abstract}




\section{Case Reports in Neurology}

Case Rep Neurol 2019;11:304-311

DOI: $10.1159 / 000504017$

2019 The Author(s). Published by S. Karger AG, Basel www.karger.com/crn

Younes et al.: Hepatic Encephalopathy Mimicking Acute Dominant Middle Cerebral Artery Ischemic Stroke: A Case Report

subcortical restricted diffusion with no cortical involvement. Due to a mismatch between the MRI findings and the neurological symptoms, she underwent digital subtraction cerebral angiography to assess candidacy for intra-arterial thrombectomy, which revealed completely patent MCAs with intact filling of the distal branches. Liver enzymes and ammonia were elevated. The patient was treated with lactulose and intravenous fluids. After normalization of liver enzymes, the patient's neurological deficits resolved. Reversal of this patient's focal symptoms with medical management could potentially be explained by the recovery of blood flowmetabolic demand mismatch caused by worsening liver dysfunction and hyperammonemia. As acute stroke therapies and interventions increase in utility for large artery acute ischemic stroke, it is vital to recognize hepatic encephalopathy and liver failure as part of the differential diagnosis for patients presenting with MCA syndrome.

\section{Introduction}

Hepatic encephalopathy and liver failure have been associated with significant neurological disorders including asterixis, delirium, and coma [1, 2]. However, focal neurological deficits in a specific vascular distribution are rarely attributed to hepatic dysfunction [3-6]. Transarterial chemoembolization (TACE) is a nonsurgical treatment for hepatocellular carcinoma (HCC) involving intra-arterial chemotherapy infusion and arterial embolization with the purpose of exhibiting cytotoxic and ischemic effects on a hepatic tumor [7]. Neurological complications can include encephalopathy and cerebral lipiodol embolism (CLE) [8-12]. We describe a case of hepatic encephalopathy associated with worsening liver function in the setting of hyperammonemia after TACE presenting with acute dominant middle cerebral artery (MCA) syndrome. MRI revealed asymmetric diffusion-weighted imaging (DWI) restricted diffusion subcortically, and the patient had an unremarkable diagnostic evaluation for ischemic stroke.

\section{Case Description}

A 59-year-old right-handed Caucasian woman without a history of clinical stroke and with a medical history of non-insulin-dependent diabetes, hypertension, hepatitis $\mathrm{C}$ virus resistant to prior treatment with interferon and ribavirin, and cirrhosis (MELD-Na score 13), complicated by hepatic hydrothorax, ascites, nonbleeding esophageal varices, and HCC, underwent a first-time and elective TACE. Prior to TACE, her HCC consisted of a single 5.4-cm left liver mass. Her TACE entailed arterial embolization with 100- to 300- $\mu$ m microspheres mixed with doxorubicin, and an uncomplicated procedure was documented after completion. Due to a transient elevation in her blood pressure $(165 / 72 \mathrm{~mm} \mathrm{Hg}$ or $22.0 / 9.6 \mathrm{kPa})$ she was admitted for observation, after which she became normotensive gradually with administration of oral furosemide $40 \mathrm{mg}$ and oral metoprolol $25 \mathrm{mg}$. There were no recorded episodes of hypotension. She remained otherwise in her normal state of health with no focal weakness or language impairment for $12 \mathrm{~h}$ after the end of her procedure. Then, she developed new- 


\section{Case Reports in Neurology}

Case Rep Neurol 2019;11:304-311

DOI: $10.1159 / 000504017$

(c) 2019 The Author(s). Published by S. Karger AG, Basel www.karger.com/crn

Younes et al.: Hepatic Encephalopathy Mimicking Acute Dominant Middle Cerebral Artery Ischemic Stroke: A Case Report

onset neurological symptoms. Her National Institutes of Health Stroke Scale score was 17. Points were given for drowsiness, expressive greater than receptive aphasia, left gaze deviation, right homonymous hemianopsia, and right hemiplegia consistent with left MCA syndrome. The patient's temperature was $97.1^{\circ} \mathrm{F}\left(36.2^{\circ} \mathrm{C}\right)$, heart rate 66 beats per minute sinus rhythm, blood pressure $117 / 58 \mathrm{~mm} \mathrm{Hg}(15.6 / 7.7 \mathrm{kPa})$, and respiratory rate 14 breaths per minute.

Initial venous labs revealed acute transaminitis, acute kidney injury, hyperammonemia, and thrombocytopenia (see Table 1, including reference ranges). Aspartate transaminase (AST) had increased from $61 \mathrm{U} / \mathrm{L}$ before TACE to $250 \mathrm{U} / \mathrm{L}$ afterward, and alanine transaminase (ALT) had increased from 51 to $61 \mathrm{U} / \mathrm{L}$. Her creatinine had increased from 1.4 to $2.3 \mathrm{mg} / \mathrm{dL}$ and BUN from 22 to $36 \mathrm{mg} / \mathrm{dL}$. Her platelet count had increased from 61 to $84 \times 10^{3} / \mathrm{cm}^{3}$. International normalized ratio was 1.29 initially (but subsequently increased to 1.48 the next day), blood glucose $137 \mathrm{mg} / \mathrm{dL}$, and ammonia level $81 \mu \mathrm{Mol} / \mathrm{L}$ at the time of neurological evaluation.

Brain CT revealed multiple subcortical patchy hypodensities concerning for age-indeterminate ischemic stroke (Fig. 1a). She was not eligible for intravenous tissue plasminogen activator due to thrombocytopenia and the age-indeterminate hypodensities on brain CT [13]. Hence, an MRI brain stroke protocol was obtained which demonstrated left greater than right subcortical restricted diffusion, particularly in the left putamen and caudate. Fluid-attenuated inversion recovery (FLAIR) sequence revealed chronic microvascular findings bilaterally, with age-indeterminate changes in some of the area of restricted diffusion, although to a lesser degree. The patient continued to exhibit disabling unilateral cortical symptoms despite the absence of cortical ischemic injury on the DWI and FLAIR sequences (Fig. 1b). Due to this marked mismatch between the patient's neurological examination and the DWI changes on MRI, she underwent digital subtraction angiography to evaluate for large vessel occlusion and consider intra-arterial therapy, which revealed completely patent vessels with an intact filling of the distal branches (Fig. 1c).

Afterward, medical resuscitation with intravenous fluids and lactulose were continued. EEG demonstrated mild diffuse slowing without epileptiform discharges. Additional diagnostic evaluation included unremarkable lipid panel, hemoglobin A1c, and telemetry. Twodimensional echocardiography was also unremarkable and without interatrial shunt. The patient developed upper and lower gastrointestinal bleeding and required banding of multiple esophageal varices. Twenty-four hours after symptom onset her ALT had decreased to $44 \mathrm{U} / \mathrm{L}$ and her AST to $150 \mathrm{U} / \mathrm{L}$. Over $48 \mathrm{~h}$ after symptom onset, the patient regained movement of her right hemi-body, and her aphasia and gaze deviation resolved. Seventy-two hours after symptom onset her AST had further decreased to $85 \mathrm{U} / \mathrm{L}$. Ammonia remained elevated at $72 \mathrm{~h}(82 \mu \mathrm{Mol} / \mathrm{L})$. She returned to her neurological baseline by the 7 th day of hospitalization.

\section{Discussion}

Neurological deficits have been reported with hepatic encephalopathy and liver failure, including focal neurological findings [1-6]. It is, however, rare for focal deficits limited to a single vascular territory to be attributed to liver decompensation. In one study with prospectively collected data, 8 out of 46 hospitalizations (17.4\%) for hepatic encephalopathy were for 


\section{Case Reports in Neurology}

Case Rep Neurol 2019;11:304-311

DOI: $10.1159 / 000504017$

2019 The Author(s). Published by S. Karger AG, Basel www.karger.com/crn

Younes et al.: Hepatic Encephalopathy Mimicking Acute Dominant Middle Cerebral Artery Ischemic Stroke: A Case Report

patients who exhibited focal neurological signs. Six of these 32 patients had hemiplegia or hemiparesis. Other focal neurological symptoms described were hemiagnosia, limb monoplegia, and seizures. None of these patients had MRI changes and all focal symptoms resolved on subsequent examination [3]. In another study, 5 out of 170 inpatients (3\%) admitted for hepatic decompensation presented with focal neurological deficits. These 5 patients comprised $15 \%$ of the 33 patients who were diagnosed with hepatic encephalopathy in this cohort. One patient demonstrated cortical blindness and agnosia and another hemiplegia, the remainder had asymmetric tone and reflexes, but not hemiparesis. This cohort of patients predated CT and MRI scans [6]. While hepatic decompensation and subsequent encephalopathy only occasionally present with symptoms consistent with stroke, it is important to include them in the differential diagnosis as acute stroke treatments such as thrombolytic and intra-arterial therapies expand.

The patient had an elevated ammonia level. Unfortunately, a baseline ammonia level was not available to us. While monitoring of ammonia levels is not recommended to diagnose or monitor hepatic encephalopathy [14], there may be some role of hyperammonemia in the patient's presentation. When elevated, ammonia is converted to glutamine by glutamine synthetase, an enzyme found in the astrocytes in the gray matter. Glutamine accumulation leads to astrocytic swelling and cerebral edema in the acutely affected brain [15-18]. Ott et al. [19] proposed that elevated ammonia levels inhibit the tricarboxylic acid cycle enzyme alpha ketoglutarate dehydrogenase, disrupting astrocytic mitochondrial energy metabolism and leading to significant cerebral protein degradation. Furthermore, restricted diffusion in the insular cortex and cingulate gyrus has been noted in patients with hyperammonemia secondary to genetically inherited errors of urea cycle metabolism [20,21]. Unlike our patient's presentation, the bilateral MRI findings in these inherited cases of hyperammonemia tended to be symmetric, and the serum ammonia levels tended to be much higher.

Several factors may have contributed to our patient's neurological symptoms. For instance, reduced MCA blood velocity has been characterized in advanced cirrhotic patients with Child-Pugh scores B or C [22]. Moreover, in a cohort study comparing cirrhotic patients with hepatic encephalopathy to both healthy subjects and cirrhotic patients without hepatic encephalopathy, patients with hepatic encephalopathy had impaired oxygen consumption and blood perfusion when comparing PET findings. Interestingly, the authors found a correlation between these findings and ammonia levels [23]. Another study utilized transcranial Doppler ultrasound to demonstrate reduced cerebral autoregulation in patients with liver failure with hepatic encephalopathy compared to those without hepatic encephalopathy [24]. MRI findings in hepatic encephalopathy can include T2 hyperintensity and even restricted diffusion in the globus pallidus; however, these are typically bilateral [25].

We make the assumption that the mismatch between the clinical examination and imaging findings could be explained by a metabolic and perfusion demand failure due to hepatic encephalopathy and decompensation in the setting of hyperammonemia, which led to transient neurological impairment of the dominant hemisphere in the absence of vascular compromise.

Additional differential diagnoses should be considered in a patient after TACE with focal neurological deficits. CLE is a rare but well-characterized complication of TACE, in which embolization of chemical agents used for TACE, but not the actual embolization microspheres, are suspected to cause brain injury [8-12]. One study estimated a CLE frequency of 1:1,000 
TACE procures [12]. CLE can present with nonspecific symptoms such as headache and confusion, but also with focal neurological symptoms [8-12]. However, in contrast to this patient's MRI findings, CLE appears to more commonly present with disseminated restricted diffusion, at or near the cortex, although also involving areas supplied by the posterior circulation $[9,11]$. Another important differential is symptomatic cerebral hypoperfusion, as the patient was treated for hypertension after TACE. However, on chart review she had no recorded hypotension and she was normotensive while symptomatic. Poststroke recrudescence in the setting of metabolic derangements could also explain the patient's symptoms, especially given the chronic microvascular and ischemic changes on MRI; however, she had never had aphasia or left-sided weakness in the past [26].

We are unfortunately limited in that we do not have diagnostic studies showing oxygen metabolism or perfusion at the time of onset nor after normalization of her neurological symptoms. We are also limited as a repeat MRI after symptom resolution was not obtained for comparison purposes. Given a diagnostic evaluation negative for thrombotic and embolic source of stroke as well as normalization of neurological examination in the setting of improved liver function and resolving encephalopathy, we inferred that the patient's focal clinical presentation was related to metabolic demand rather than a thrombotic event, which is essential with the rising evidence of increased risk for ischemic stroke in cirrhotic, hepatitis $\mathrm{C}$, and fatty liver patients [27-29]. How hyperammonemia and acute liver failure lead to lateralized neurological symptoms is unclear and warrants further investigation.

In summary, we discuss a case of hepatic encephalopathy in the setting of hyperammonemia and liver decompensation presenting as reversible acute dominant MCA stroke syndrome. We infer that this stroke mimic can be explained by impaired metabolism and autoregulatory and perfusion deficits. This case demonstrates the importance of distinguishing noncerebrovascular stroke mimics from actual ischemic stroke and highlights the need to carefully consider the predicted underlying pathophysiology when evaluating patients exhibiting stroke-like symptoms. In this patient population, we suggest testing for ammonia level, liver enzymes, and coagulopathy as part of the acute stroke evaluation, without delaying potential acute stroke therapies and interventions.

\section{Statement of Ethics}

The patient gave her informed consent and the case report was approved by the institute's committee on human research.

\section{Disclosure Statement}

The authors have no competing interests or disclosures. 


\section{References}

1 Felipo V. Hepatic encephalopathy: effects of liver failure on brain function. Nat Rev Neurosci. 2013 Dec;14(12):851-8.

2 Adams RD, Foley JM. The neurological disorder associated with liver disease. Res Publ Assoc Res Nerv Ment Dis. 1953;32:198-237.

3 Cadranel JF, Lebiez E, Di Martino V, Bernard B, El Koury S, Tourbah A, et al. Focal neurological signs in hepatic encephalopathy in cirrhotic patients: an underestimated entity? Am J Gastroenterol. 2001 Feb;96(2): 515-8.

4 Atchison JW, Pellegrino M, Herbers P, Tipton B, Matkovic V. Hepatic encephalopathy mimicking stroke. A case report. Am J Phys Med Rehabil. 1992 Apr;71(2):114-8.

5 Yamamoto Y, Nishiyama Y, Katsura K, Yamazaki M, Katayama Y. Hepatic encephalopathy with reversible focal neurologic signs resembling acute stroke: case report. J Stroke Cerebrovasc Dis. 2011 Jul-Aug;20(4): 377-80.

6 Pearce JM. Focal Neurological Syndromes in Hepatic Failure. Postgrad Med J. 1963 Nov;39(457):653-7.

7 Lencioni R. Chemoembolization for hepatocellular carcinoma. Semin Oncol. 2012 Aug;39(4):503-9.

8 Berger DH, Carrasco CH, Hohn DC, Curley SA. Hepatic artery chemoembolization or embolization for primary and metastatic liver tumors: post-treatment management and complications. J Surg Oncol. 1995 Oct;60(2):116-21.

9 Yoo KM, Yoo BG, Kim KS, Lee SU, Han BH. Cerebral lipiodol embolism during transcatheter arterial chemoembolization. Neurology. 2004 Jul;63(1):181-3.

10 Wu L, Yang YF, Liang J, Shen SQ, Ge NJ, Wu MC. Cerebral lipiodol embolism following transcatheter arterial chemoembolization for hepatocellular carcinoma. World J Gastroenterol. 2010 Jan;16(3):398-402.

11 Zach V, Rapaport B, Yoo JY, Goldfeder L, Weinberger J. Multiple ischemic strokes after transcatheter arterial chemoembolization for hepatocellular carcinoma with a radiographic and pathological correlate. J Stroke Cerebrovasc Dis. 2012 Apr;21(3):217-24.

12 Chu HJ, Lee CW, Yeh SJ, Tsai LK, Tang SC, Jeng JS. Cerebral lipiodol embolism in hepatocellular carcinoma patients treated with transarterial embolization/chemoembolization. PLoS One. 2015 Jun 24;10(6): e0129367.

13 Demaerschalk BM, Kleindorfer DO, Adeoye OM, Demchuk AM, Fugate JE, Grotta JC, et al.; American Heart Association Stroke Council and Council on Epidemiology and Prevention. Scientific Rationale for the Inclusion and Exclusion Criteria for Intravenous Alteplase in Acute Ischemic Stroke: A Statement for Healthcare Professionals From the American Heart Association/American Stroke Association. Stroke. 2016 Feb;47(2):581-641.

14 Ge PS, Runyon BA. Serum ammonia level for the evaluation of hepatic encephalopathy. JAMA. 2014 Aug;312(6):643-4.

15 Felipo V, Butterworth RF. Neurobiology of ammonia. Prog Neurobiol. 2002 Jul;67(4):259-79.

16 Voorhies TM, Ehrlich ME, Duffy TE, Petito CK, Plum F. Acute hyperammonemia in the young primate: physiologic and neuropathologic correlates. Pediatr Res. 1983 Dec;17(12):970-5.

17 Cooper AJ. The role of glutamine synthetase and glutamate dehydrogenase in cerebral ammonia homeostasis. Neurochem Res. 2012 Nov;37(11):2439-55.

18 Brusilow SW. Disorders of the urea cycle. Hosp Pract (Off Ed). 1985 Oct;20(10):65-72.

19 Ott P, Clemmesen O, Larsen FS. Cerebral metabolic disturbances in the brain during acute liver failure: from hyperammonemia to energy failure and proteolysis. Neurochem Int. 2005 Jul;47(1-2):13-8.

20 Wong YC, Au WL, Xu M, Ye J, Lim CC. Magnetic resonance spectroscopy in adult-onset citrullinemia: elevated glutamine levels in comatose patients. Arch Neurol. 2007 Jul;64(7):1034-7.

21 Takanashi J, Barkovich AJ, Cheng SF, Kostiner D, Baker JC, Packman S. Brain MR imaging in acute hyperammonemic encephalopathy arising from late-onset ornithine transcarbamylase deficiency. AJNR Am J Neuroradiol. 2003 Mar;24(3):390-3.

22 Dillon JF, Plevris JN, Wong FC, Chan KH, Lo NT, Miller JD, et al. Middle cerebral artery blood flow velocity in patients with cirrhosis. Eur J Gastroenterol Hepatol. 1995 Nov;7(11):1087-91.

23 Iversen P, Sørensen M, Bak LK, Waagepetersen HS, Vafaee MS, Borghammer P, et al. Low cerebral oxygen consumption and blood flow in patients with cirrhosis and an acute episode of hepatic encephalopathy. Gastroenterology. 2009 Mar;136(3):863-71.

24 Strauss GI, Hansen BA, Herzog T, Larsen FS. Cerebral autoregulation in patients with end-stage liver disease. Eur J Gastroenterol Hepatol. 2000 Jul;12(7):767-71.

25 Rovira A, Alonso J, Córdoba J. MR imaging findings in hepatic encephalopathy. AJNR Am J Neuroradiol. 2008 Oct;29(9):1612-21. 


\section{Case Reports in Neurology}

\begin{tabular}{|c|c|}
\hline DOI: 10.1159/000504017 & $\begin{array}{l}\text { (c) } 2019 \text { The Author(s). Published by S. Karger AG, Basel } \\
\text { www.karger.com/crn }\end{array}$ \\
\hline
\end{tabular}

Younes et al.: Hepatic Encephalopathy Mimicking Acute Dominant Middle Cerebral Artery Ischemic Stroke: A Case Report

26 Topcuoglu MA, Saka E, Silverman SB, Schwamm LH, Singhal AB. Recrudescence of Deficits After Stroke: Clinical and Imaging Phenotype, Triggers, and Risk Factors. JAMA Neurol. 2017 Sep;74(9):1048-55.

27 Zhang X, Qi X, Yoshida EM, Méndez-Sánchez N, Hou F, Deng H, et al. Ischemic stroke in liver cirrhosis: epidemiology, risk factors, and in-hospital outcomes. Eur J Gastroenterol Hepatol. 2018 Feb;30(2):233-40.

28 He H, Kang R, Zhao Z. Hepatitis C virus infection and risk of stroke: a systematic review and meta-analysis. PLoS One. 2013 Nov;8(11):e81305.

29 Papagianni M, Tziomalos K. Non-alcoholic fatty liver disease: an emerging predictor of stroke risk, severity and outcome. Eur J Neurol. 2018 Apr;25(4):610-1.
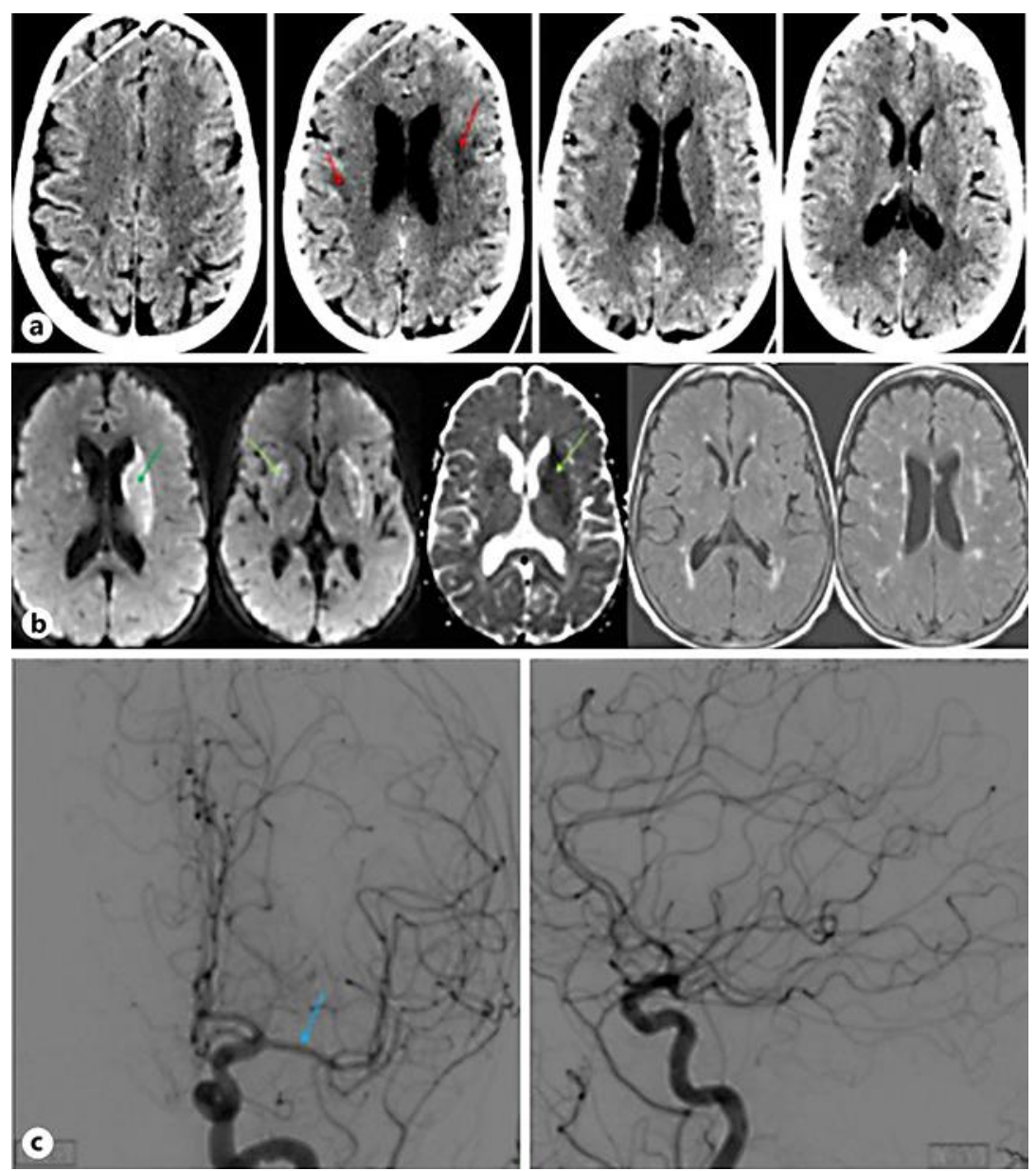

Fig. 1. a Brain CT revealed multiple subcortical patchy hypodensities (red arrows). b MRI demonstrated predominantly left-sided diffusion restriction in the basal ganglia (green arrows) without correlating fluidattenuated inversion recovery abnormalities. c Patent middle cerebral artery vasculature based on cerebral angiography (blue arrow). 
Table 1. Serum venous laboratory values

\begin{tabular}{|c|c|c|c|c|c|}
\hline & $\begin{array}{l}\text { Before } \\
\text { TACE }\end{array}$ & $\begin{array}{l}\text { Symptom } \\
\text { onset (12 h } \\
\text { after TACE) }\end{array}$ & $\begin{array}{l}24 \mathrm{~h} \text { after } \\
\text { symptom } \\
\text { onset }\end{array}$ & $\begin{array}{l}48 \mathrm{~h} \text { after } \\
\text { symptom } \\
\text { onset }\end{array}$ & $\begin{array}{l}72 \mathrm{~h} \text { after } \\
\text { symptom } \\
\text { onset }\end{array}$ \\
\hline ALT (ref. 0-65 U/L) & 51 & 61 & 44 & NA & 45 \\
\hline AST (ref. 0-37 U/L) & 61 & 250 & 150 & NA & 85 \\
\hline Direct bilirubin (ref. $0.0-0.3 \mathrm{mg} / \mathrm{dL}$ ) & 0.6 & 0.3 & 0.9 & NA & 0.9 \\
\hline Ammonia (ref. $\leq 45.0 \mu \mathrm{Mol} / \mathrm{L}$ ) & NA & 81.0 & NA & NA & 82.0 \\
\hline INR (ref. 0.85-1.17) & 1.29 & 1.29 & 1.48 & NA & 1.48 \\
\hline PT (ref. 12.0-14.7 s) & 16.2 & 16.2 & 18.2 & NA & 18.2 \\
\hline Platelets (ref. $133-450 \times 10^{3} / \mathrm{cm}^{3}$ ) & 61 & 84 & 53 & 41 & 44 \\
\hline Lactic acid (ref. 0.5-2.2 mMol/L) & NA & 1.4 & NA & NA & 1.3 \\
\hline Creatinine (ref. $0.5-1.4 \mathrm{mg} / \mathrm{dL}$ ) & 1.4 & 2.3 & 2.3 & 1.8 & 1.5 \\
\hline Blood sugar (ref. 70-99 mg/dL) & 144 & 137 & 92 & 137 & 170 \\
\hline
\end{tabular}

ALT, alanine transaminase; AST, aspartate transaminase; INR, international normalized ratio; NA, not available; PT, prothrombin time; ref., reference range; TACE, transarterial chemoembolization. 